\title{
CRÔNICA DAS ARCADAS
}

\author{
Novo Diretor para as Arcadas, \\ Professor Doutor Vicente Marotta Rangel
}

\section{A Redação}

\begin{abstract}
A 11 de agosto de 1982, quando se comemorava - centésimo quiinquagésimo quinto aniverśríto de fundação dos Cursos Jurídicos no Brasil, foi recebic̀o solenemente pela Congregação de Professores da Faculdade de Direito da Universidade de São Paulo - seu 330 Diretor, o eminente catedrático de Direito Internacional, Vicente Marotta Rangel.

Homem experiente - ex-vice-diretor da ECA-USP, ex-coordenador dos cursos de Pós-Graduação, dentre outros -, o novo Diretor das Arcadas manifestou em seu discurso de posse o proposito de fortalecer 0 processo de continuidade da história acadêmica que tem marcado e refulgido o ámbito da Faculdade, território movimentado na busca e aprofundamento de sua riqueza interior, na sociedade.

Agradeceu a honrosa deferência, relembrando que passados cento e cinqüenta e cinco anos, decorridos desde a fundação da Faculdade de Direito, vê-se como o sucessor do tenente-general José Arouche de Toledo Rendon, comprometendo-se, no final, diligenciar para que a Faculdade prossiga no roteiro de suas tradições e na consecução de seus altos objetivos, a serviço da missão mais abrangente e integrante da Universidade de são Paulo.
\end{abstract}

\section{A Faculdade de Direito e a Comunidade Universitária (*)}

O fato de alçar-me, no contexto ritual desta solenidade, à direção da Faculdade de Direito da Universidade de São Paulo se insere dentro de linhas de perspectiva mestras que convergem para este momento crucial e solene, em que assumo o compromisso de gerir a tradicional Casa de Ensino do Largo de São Francisco. Tal compromisso significa reconhecer de início ser ele próprio a resultante de uma soma de gestos, de idéias e de decisões sucessivos pelos quais desejo mani-

* Discurso na Solenidade de Posse como Diretor da Faculdade de Direito, dia 15-07-1982, na Reitoria da Universidade de São Paulo. 
festar agradecimentos, os quais se endereçam em primeiro lugar quer ao Magnífico Reitor - e este é o local e o momento de externá-lo vigorosamente, quer à Colenda Congregação de minha Escola, pois ambos me distinguiram sobremodo, respectivamente, com a dignidade da investidura e com a cortezia da proposta. Tais agradecimentos desejaria consignar na pessoa dos eminentes colegas que compuseram a lista sêxtupla assim como na pessoa de cada um dos demais ilustres docentes da mais antiga Escola de nossa Universidade. Almejaria estender esses agradecimentos a todos quantos aqui se encontram nesta sala, que me obsequiam com o penhor de sua amizade e o conforto de sua presença, diretores de unidades, coordenadores, colegas, professores, funcionários, amigos, todos testemunhos e caminhantes de jornadas comuns, diversas, de trajetos de percursos vários e de irradiações para distintos pontos cardeais, todos caminhantes do bom caminho; desses que muitas vezes se fazem, como queria o poeta, não com aprendizado prévia e orientação específica, mas pelo simples fato de caminhar.

Aluno que fui da Faculdade de Direito, em que me diplomei e à qual regressei como integrante de seu quadro de professores, e no qual percorri, degrau por degrau, a áspera vertente da carreira universitária, sinto nela integrar-me e ela em mim integrar-se de modo pleno e substancial. Vocação irresistivel me impulsionou aos seus pórticos. Cada vez que lhe adentrava os umbrais, o fazia reverente e comovido, tocado pelo simbolismo das Arcadas, que hoje revejo de modo mais objetivo e impessoal. Foi sob o influxo de debates, propícios a uma quadra universitária conturbada, que me dediquei aos estudos sem deixar de participar da vida acadêmica. Foi sob o influxo do ensino assim como das discussões, do frêmito das salas, do pátio e dos anfiteatros que os estudantes das Arcadas me elegeram orador oficial do Centro Acadêmico XI de Agosto e meus colegas de turma me distinguiram com a indicação para orador na cerimônia de colação de grau. Vão longe esses tempos mas é grato recordá-los na perspectiva de um novo reencontro com a Faculdade de Direito, desta feita ao adentrar-lhe as Arcadas como seu novo diretor.

Cento e cincoenta e cinco anos decorridos desde a fundação da Faculdade de Direito, vejo-me hoje sucessor do tenente-general José Arouche de Toledo Rendon, nomeado por decreto de 13 de outubro de 1827. Entre o tenente-general e o orador que vos fala permeiam mais de século e meio de existência bem como a sucessão de mais de três dezenas de diretores, dos quais sou, a rigor, o trigésimo terceiro. Parece valiosa e mesmo necessária a compreensão deste momento dentro dos quadrantes da história, sem a qual perde sentido o alcance da investidura e o destino da missão a cumprir. Sem a integração desta solenidade no que Mouravieff chamou "a curva harmoniosa do desenvolvimento lógico da história" poderia permanecer constante a incógnita dessas "linhas quebradas que a atividade anárquica do homem" está incessantemente a gerar. Para usar de classificação 


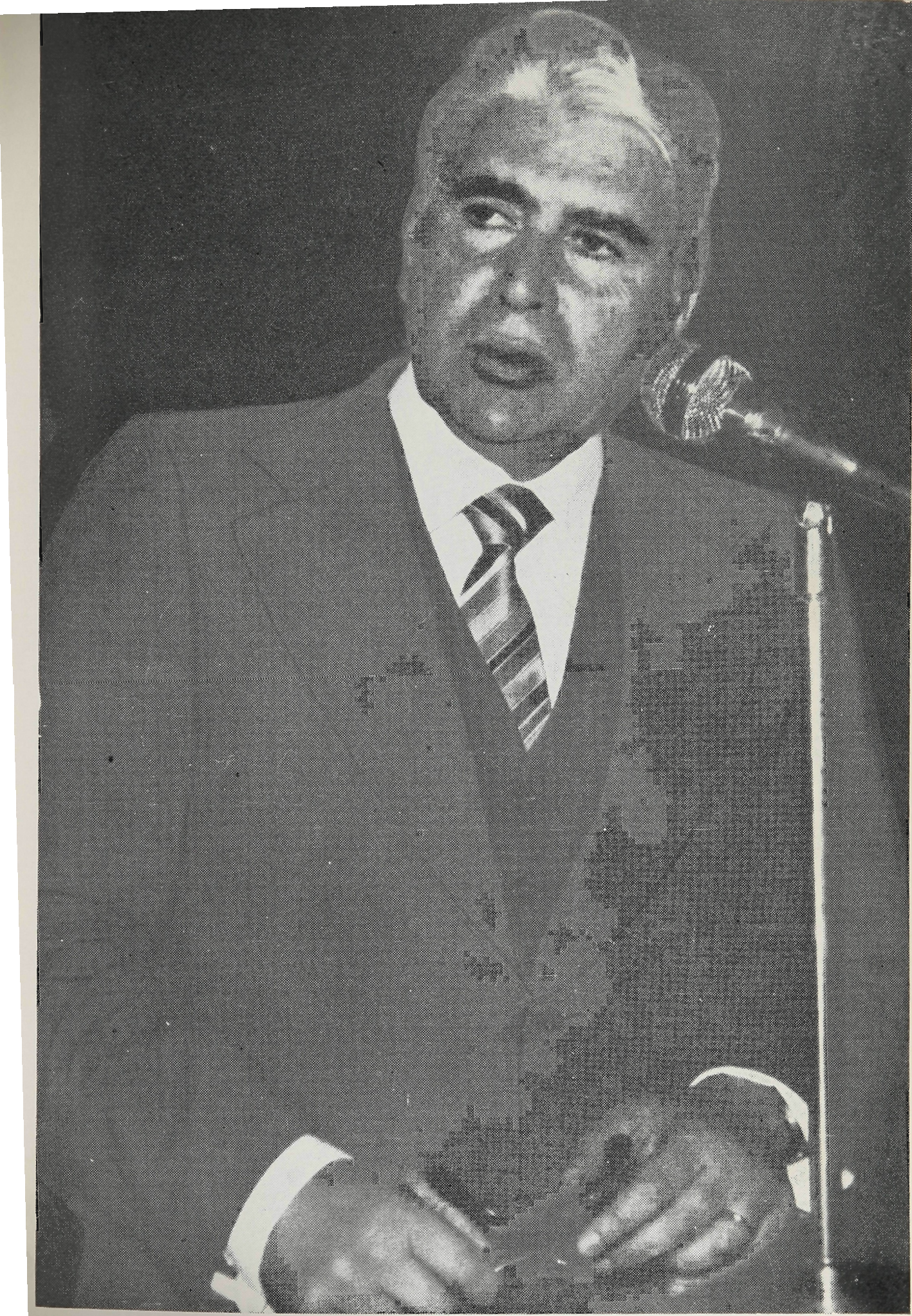

Novo Diretor da Faculdade,

Professor Dr. Vicente Marotta Rangel 
fecunda perfilhada por Miguel Reale, antigo Reitor desta Universidade, tem base nos fatos vitais registrados na historiografia brasileira a caracterização da Faculdade de Direito não como entidade que "apenas flua no tempo carente de autêntico sentido existencial" mas como instituição que perdura na plena luz de sua continuidade vetorial, pela força de atualização do passado no momento conscientemente vivido".

De tal classificação honrosa participam, aliás, igualmente a Universidade de São Paulo quer em si mesma como um todo quer na força e presença das unidades que a integram.

A procedência das indicações hauridas durante o meu lustre acadêmico, inspirada em processo de escolha de colegas, e continuadas sem cessar novamente no âmbito da Congregação, se mostrou sempre coerente com as convicções democráticas que, mercê de Deus, jamais traí. Compreendi, desde cedo, que o grau de representatividade não possui caráter definitivo ou sacral mas carece de ser posto constantemente à prova. A representatividade se dilui em meras aparências e ficções, e tende a deteriorar-se na rotina dos comodismos fáceis, se não robustecer-se, por seu turno, na forja das provações e dos aperfeiçoamentos contínuos. Daí a necessidade do estudo, do saber feito de experiência, da vivência constante com as teorias e sobretudo com os fatos. Períodos sucessivos de estudos de pós-graduação em diferentes países estrangeiros, acompanhados da prática da advocacia e do magistério e intercalados com labor em fábricas e sindicatos me ajudaram a compreender a natureza dos problemas que conturbam o homem e a sociedade, os quais têm concorrido para a gestação das crises de estrutura e de valores cujas repercussões na paisagem do ensino e da pesquisa são de todos bastante conhecidas. Na raiz dessas crises se põe sempre a questão da legitimidade do poder, que deve ser entendida no seu aspecto substancial e não retórico, na sua realidade profunda e não apenas fenomenológica.

Chefe do Departamento e Coordenador dos Cursos de Pós-Graduação da Faculdade de Direito, gestão de Escola mantida por Fun. dação privada, vice-diretor de nossa Escola de Comunicações e Artes, tudo isso concorreu para que, gradualmente, a experiência administrativa pudesse ser completada com a visão fecunda de harmonia, integração e desenvolvimento de Unidades no complexo mais geral e dinâmico da Universidade de São Paulo, dessa Universidade que sobressai por seu nivel de excelência no panorama nacional complexo e muitas vezes decepcionante de cerca de seis dezenas de Universidades e de oito centenas de institutos isolados que se distribuem pela vastidão do território brasileiro.

"O espírito científico" - como bem o enunciou o Magnífico Reitor em seu discurso de posse - " "deverá sempre prevalecer sobre interesses políticos, econômicos ou outros de quaisquer natureza; assim como a liberdade acadêmica que mantém a Universidade em sua posição 
crítica para a discussão científica, política ou econômica". Alegra-me verificar que o princípio do espírito científico e o da liberdade acadêmica foram inspiradores de minha gestão na Coordenadoria de Atividades Acadêmicas da Reitoria da Universidade de São Paulo, função essa em que usufrui da confiança dos reitores Professor Orlando Marques de Paiva e Waldyr Muniz Oliva aos quais agradeço de público, nesta oportunidade, confiança essa em que o atual Reitor me reitera ao designar-me para a direção da Faculdade de Direito.

Integrada, juntamente com as demais unidades irmãs no processo de ensino e de pesquisa da Universidade de São Paulo, a Faculdade de Direito tem se esmerado, mercê da diligência de seus sucessivos diretores, em dar sua contribuição para a ativação desse processo. É o que também me proponho fazer, imprimindo ao processo - como é natural - a marca pessoal de minha vivência anterior e de muitas expectativas em relação ao futuro próximo. Na consecução das metas a atingir, parece-me que cabe à Faculdade de Direito, cada vez mais, inspirar-se em tríplice signo: o signo da unidade, voltada para si própria, na busca e aprofundamento de sua riqueza, na perquirição da potencialidade de seus Departamentos, da capacidade atuante de seus docentes, de seus alunos, de seus funcionários; o signo da Universidade, como elemento integrante e solidário no processo global de ensino, de pesquisa e de prestação de serviço à comunidade; e finalmente o signo da universidade pois a Faculdade, como a própria Universidade, é fulcro altaneiro e arejado, sensível ao sopro das aspirações e inquietudes que perpassam em nosso país e alhures. Sem essa universidade, a Universidade decairia de suas funçõec precípuas e quedaria inerte no exaurimento de si própria.

Comunitária é a Universidade, a começar pelo fato de que todos que para ela convergem se sentem chamados por uma vocação intelectual, que para dominar sobre as adversidades, importa seja poderosa, autêntica, integradora, e dela participe igualmente o conjunto de alunos e de professores: Universitas magistrorum et studentium. A tentação atroz que costuma assediar liminarmente a Universidade é precisamente a de que, embalada pelo academismo, impregnada pela visão particularista dos problemas, se esvazie de seu conteúdo comunitário. É a mesma tentação a rondar o próprio intelectual, o isolamento que o priva de ouvir, em torno de si, o murmurar das inquietudes do próximo, os reclamos concretos do gênero humano, em suma, o encastelamento em sua própria torre de marfim. Se o conhecimento científico reclama especialização, se toda especialização tende a ser fecunda e necessária, certo é, no entanto, que ela pode conduzir a compartimentos estanques em que o saber se estiole, por carência da seiva inspiradora das relações sociais. Não há verdades isoladas, seccionadas uma das outras. Todas as verdades se entrelaçam, acabam confundindo-se numa só. Por este ou aquele afluente, acabaremos por aportar em alto mar, a que convergem os valores transcendentais nas quais a alma humana intenta saciar sua sede inquieta e infinita. 
Minhas Senhoras e Meus Senhores.

No ato de convergência comunitária, que é a marca desta solenidade, desejo renovar agradecimentos pela honrosa deferência de que sou alvo e comprometer-me a diligenciar para que a Faculdade de Direito prossiga no roteiro de suas tradições e na consecução de seus altos objetivos, a serviço da missão mais abrangente e integrante da Universidade de São Paulo. Se o emblema de nossa Universidade é Scientia Vinces, a Faculdade de Direito, no mandato de gestão que ora se inicia, continuará a concorrer, tal como as anteriores, para que, em seu próprio âmbito, em colaboração com as unidades irmãs, e em atendimento aos mais gerais reclamos do país, a ciência se galardoe com o esplendor da sua vitória constantemente reiterada pois para tanto sofre permanente desafio - em prol do bem, da justiça e da verdade. 